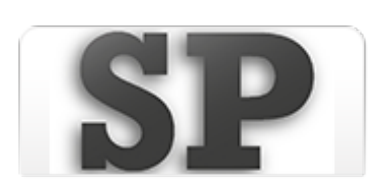

Sociedades precapitalistas

ISSN: 2250-5121

publicaciones@fahce.unlp.edu.ar

Universidad Nacional de La Plata

Argentina

\title{
Reseña del libro José Manuel Triano Milán, La llamada del rey y el auxilio del reino. Del pedido regio a las contribuciones de la Santa Hermandad (1406-1498), Sevilla, Editorial Universidad de Sevilla, 2018. (753 pág.)
}

\section{Luchía, Corina}

Reseña del libro José Manuel Triano Milán, La llamada del rey y el auxilio del reino. Del pedido regio a las contribuciones de la Santa Hermandad (1406-1498), Sevilla, Editorial Universidad de Sevilla, 2018. (753 pág.)

Sociedades precapitalistas, núm. 9, 2020

Universidad Nacional de La Plata, Argentina DOI: https://doi.org/10.24215/22505121e048

Atribución no comercial compartir igual (CC BY-NC-SA) 4.0 


\section{Reseña del libro José Manuel Triano Milán, La llamada del rey y el auxilio del reino. Del pedido regio a las contribuciones de la Santa Hermandad (1406-1498), Sevilla, Editorial Universidad de Sevilla, 2018. (753 pág.)}

Corina Luchia

DOI: https://doi.org/10.24215/22505121e048

Instituto de Historia de España, Universidad de Buenos

Aires-CONICET, Argentina

corinaluchia@filo.uba.ar

Triano Milán José Manuel. La llamada del rey y el auxilio del reino. Del pedido regio a las contribuciones de la Santa Hermandad (1406-1498). Sevilla. Editorial Universidad de Sevilla. 753 pp. Recepción: 16 Noviembre 2019

Aprobación: 15 Abril 2020

A primera vista un estudio sobre los impuestos y las finanzas estatales podría resultar árido, cuando no hostil, para quienes no se especialicen en el tema. Sin embargo, La llamada del rey y el auxilio del reino de José Manuel Triano Milán captura la atención del lector desde las primeras páginas.

La presión tributaria, el papel del Estado en la gestión de los recursos, las corruptelas de los agentes del fisco, la evasión impositiva son algunos de los asuntos más recurrentes de la agenda pública de las sociedades contemporáneas; de allí, la actualidad de este libro y el interés que puede suscitar no solo entre los medievalistas. En esta investigación los problemas estrictamente tributarios se enlazan con una profunda indagación de las lógicas de construcción estatal, la articulación y el diálogo entre los distintos poderes e instituciones, los efectos sociales y económicos de las múltiples formas de punción fiscal sobre contribuyentes de diversa condición. Más aún, los fundamentos ideológicos que justifican estas obligaciones también tienen un lugar en este extenso y erudito trabajo editado recientemente por la Universidad de Sevilla.

El derrotero de los servicios de Cortes y, tras su quiebre, el de la Santa Hermandad -ese "polivalente organismo"- son los ejes por los que discurre este aporte indispensable para el conocimiento de la fiscalidad extraordinaria castellana a lo largo del siglo XV, con especial preocupación por el caso hispalense. Las necesidades coyunturales, habitualmente vinculadas a situaciones bélicas, aparecen como la primera motivación que legitima estas contribuciones. Sin embargo, progresivamente otras circunstancias serán determinantes. Los cambiantes y por momentos críticos balances políticos del reino, el crecimiento de los aparatos burocráticos y los requerimientos del proceso de "centralización" monárquica serán claves en la exigencia de estas imposiciones, que cada vez más toman distancia de sus objetivos originarios.

En el recorrido por las diferentes etapas que atraviesan las cargas regias sobresale la dimensión transaccional del sistema recaudatorio castellano. Presionar y negociar, exigir y ceder parecen ser prácticas habituales de los distintos actores implicados en este proceso. Todo este cuadro es presentado dentro de una descripción densa en la que el acontecimiento se entrelaza con las dinámicas políticas y sociales más profundas.

A través del exhaustivo análisis bibliográfico y documental -especialmente de los padrones disponibles y de los mecanismos de recaudación- es posible trascender el plano estrictamente fiscal y reconocer desde allí la composición de las estructuras sociales locales; así como advertir las tensiones subyacentes, actualizadas, en ocasiones peligrosamente, por la voracidad impositiva de la Corona. La desigual distribución del esfuerzo tributario entre los concejos urbanos y sus respectivos alfoces, la conflictiva presencia de grupos exentos que 
pugnan por mantener o incluso ampliar sus franquezas no solo afectan las arcas regias, sino que señalan las contradicciones que vertebran todo el régimen social castellano en la decimoquinta centuria.

A lo largo de los seis capítulos que integran este libro también se abordan aquellos aspectos del "negocio fiscal" ignorados por las lecturas tradicionales: ese campo difuso entre "lo público" y "lo privado", como lo caracteriza el autor, a través del cual es posible acceder a todo tipo de prácticas fraudulentas, discrecionales y abusivas no solo de los agentes encargados de la gestión de los tributos, sino también de los propios contribuyentes y de los beneficiarios del gasto de las cantidades recaudadas. Pero el análisis no se limita a observar la generalización de actuaciones ambiguas respecto de la ley, o bien abiertamente contrarias a ella, sino que identifica dentro de una trama jerárquica a quienes disponen de condiciones favorables para realizarlas. La centralidad que adquieren en este punto las elites concejiles, tanto sus grupos dirigentes como las minorías que gozan de una posición económica aventajada, resulta un elemento insoslayable. En la misma dirección, el énfasis en el compromiso de los oficiales pecheros en el proceso de exacción señala la complejidad del sistema que articula el vértice superior del reino con las instituciones concejiles y las pequeñas entidades locales.

Los efectos de las cargas extraordinarias sobre la población pechera constituyen un objeto generalmente subordinado en la agenda de los especialistas a la indagación de otras cuestiones; sin embargo, aquí asumen un lugar privilegiado. Un arduo y complejo trabajo cuantitativo, plasmado en una serie de cuadros que presentan de forma sucinta los principales datos recabados, se enriquece con una lectura cualitativa inteligente y por momentos audaz de la información disponible. En este punto sobresale uno de los logros más significativos de esta investigación: la constante advertencia del autor respecto de las limitaciones de las fuentes con las que cuenta; frente a las cuales sostiene una permanente -y necesaria- mirada crítica.

Cuando los archivos solo aportan dudas o silencios, Triano Milán propone interrogantes. El razonamiento conjetural asume en muchos pasajes un lugar relevante; y con ello no solo supera las dificultades de una base erudita que en muchos aspectos se presenta esquiva, sino que amplía la mirada, construyendo hipótesis en base a la articulación lógico e histórica de los fenómenos estudiados. Así, por ejemplo, se sugiere que el menor peso de la fiscalidad extraordinaria en el ámbito señorial puede ser entendido como "una suerte de compensación económica" dada a los nobles a cambio de la incorporación de sus territorios al sistema hermandino. Las preguntas que plantea esta investigación abren de este modo un fructífero campo de trabajo a futuro.

Me permito, para finalizar, una breve consideración surgida de la personal lectura del libro que reseñamos. En tiempos en los cuales las usinas ideológicas del liberalismo no cejan en su afán de instalar un sentido común respecto de la rapacidad del estado como la responsable de las dificultades económicas por las que atraviesan los distintos países, fundamentalmente en las periferias capitalistas, preguntarnos por la "desigualdad fiscal" y por el destino de los recursos extraídos a las diferentes clases involucra mucho más que una preocupación técnico-administrativa en torno del funcionamiento de las maquinarias públicas. Al igual que en este siglo $\mathrm{XV}$, magníficamente estudiado por Triano Milán, las relaciones de clase y el carácter de los estados, dentro de un complejo escenario mundial, configuran la sustancia del problema. Solo desde esta perspectiva es posible comprender el debilitamiento de los consensos que antecede a los cada vez más dramáticos conflictos actuales. Celebramos la publicación de este riguroso estudio que profundiza el conocimiento de la Edad Media y a su vez estimula reflexiones sobre el presente.

\section{BY-NC-SA}

